\title{
HOUSEHOLD-BASED CERAMIC WATER FILTERS FOR THE PREVENTION OF DIARRHEA: A RANDOMIZED, CONTROLLED TRIAL OF A PILOT PROGRAM IN COLOMBIA
}

\author{
THOMAS CLASEN,* GLORIA GARCIA PARRA, SOPHIE BOISSON, AND SIMON COLLIN \\ Department of Infectious and Tropical Diseases, London School of Hygiene and Tropical Medicine, London, United Kingdom; \\ Oxfam GB, Oxford, United Kingdom; International Health Research Associates, London, United Kingdom
}

\begin{abstract}
Household water treatment is increasingly recognized as an effective means of reducing the burden of diarrheal disease among low-income populations without access to safe water. Oxfam GB undertook a pilot project to explore the use of household-based ceramic water filters in three remote communities in Colombia. In a randomized, controlled trial over a period of six months, the filters were associated with a $75.3 \%$ reduction in arithmetic mean thermotolerant coliforms (TTCs) $(P<0.0001)$. A total of $47.7 \%$ and $24.2 \%$ of the samples from the intervention group had no detectible TTCs/100 mL or conformed to World Health Organization limits for low risk (1-10 TTCs/100 mL), respectively, compared with $0.9 \%$ and $7.3 \%$ for control group samples. Overall, prevalence of diarrhea was $60 \%$ less among households using filters than among control households (odds ratio $=0.40,95 \%$ confidence interval $=0.25,0.63$, $P<0.0001)$. However, the microbiologic performance and protective effect of the filters was not uniform throughout the study communities, suggesting the need to consider the circumstances of the particular setting before implementing this intervention.
\end{abstract}

\section{INTRODUCTION}

Unsafe drinking water is a leading cause of preventable disease, particularly among low-income children in developing countries. Water-borne pathogens, including a variety of viral, bacterial, and protozoan agents, account for much of the estimated 4 billion cases and 2.5 million deaths from endemic diarrheal disease each year. ${ }^{1}$ Among children less than five 5 years of age in developing countries, diarrheal disease accounts for $21 \%$ of all deaths. ${ }^{2}$ With an estimated prevalence of $13.9 \%$ among children less than five years of age, diarrheal disease is a leading cause of morbidity and mortality in Colombia. ${ }^{3}$

More than one billion people currently lack access to any form of improved water supply within $1 \mathrm{~km}$ of their homes. ${ }^{4}$ Many more lack access to safe water. Efforts to deliver safe and reliable water services necessary to create a healthy living environment and other benefits for people in developing countries are an essential long-term goal. However, recent research has shown that the treatment and safe storage of water in the home can achieve much of the health gains associated with improved water, in many cases more effectively than conventional piped-in water. ${ }^{5,6}$ Research on the economics of such interventions also suggests that householdbased water treatment is among the most cost-effective approaches in preventing diarrheal disease. ${ }^{7}$

Oxfam GB has been working in Colombia for more than 20 years. Among other things, Oxfam supports vulnerable communities affected by the armed conflict with housing, food security, and public health initiatives, including water and sanitation. Based on successes in other Andean trials, Oxfam elected to pilot the use of ceramic water filters in three remote communities due mainly to their potential for providing safe drinking water to the affected region over longer periods of time with minimal support. ${ }^{8}$ It asked the investigators to conduct this assessment of the microbiologic performance and health impact of the filters.

* Address correspondence to Thomas Clasen, London School of Hygiene and Tropical Medicine, Keppel Street, London WC1E 7HT, United Kingdom. E-mail: thomas.clasen@1shtm.ac.uk

\section{MATERIALS AND METHODS}

Study sites. Three separate communities representing different circumstances and challenges were selected by Oxfam for the pilot program. Vigía de Curvaradó, the most remote of the sites, is a fishing village with approximately 350 inhabitants along the Atrato River in the Department of Chocó. Inhabitants have a poor and unbalanced diet, and there is considerable illness, especially among infants and children. Homes are built on stilts over the water and inhabitants spend much of the day on or around the river. The river is the source of all water needs, including washing water, human and other waste disposal, and, except for periodic rain harvesting, drinking water. When thirsty, many inhabitants, and especially children, consume water directly from the river.

Dabeiba is a town with approximately 30,000 inhabitants located in a mountainous region of the Department of Antioquia. Most inhabitants raise crops and livestock. Water used for drinking and all other purposes is supplied by a gravity-fed aqueduct. An antiquated and poorly maintained pipe distribution system supplies water to yard taps, but because of poor service, inhabitants collect and store water in open vessels used for humans and livestock. The municipality has a water treatment facility but uses only alum as a flocculant and does not disinfect the water.

Cartagenita is a coffee-growing community of approximately 105 families in the Department of Norte de Santander who have recently returned after having been displaced due the armed conflict in Colombia. Water is supplied from a mountain stream through a series channels and storage ponds and is sent into a piped distribution network to taps at most household plots. The water is not treated, either by sedimentation, disinfection, or other means.

All three sites are in areas affected by the armed conflict in Colombia. Security problems make it impossible for Oxfam to establish and maintain consistent programmatic activities regarding water, sanitation, and hygiene. Due to both the conflict and their remoteness, Vigía de Curvaradó and Dabeiba receive less regular follow-up and programmatic support than Cartagenita. Only in Cartagenita has Oxfam been able to establish a network of health promoters who reside 
locally and therefore visit the area regularly, monitoring health and providing support.

After meeting with community representatives and performing an initial analysis of water samples, 140 households were recruited to participate in the study, 49 from Vigía de Curvaradó, 51 from Dabeiba, and 40 from Cartagenita. Participating families were selected by lottery from among those who attended an initial meeting to learn about the filters and the study. Field workers then collected baseline information from the head of each participating household by means of a standard questionnaire, and obtained a sample of the preintervention drinking water for baseline data purposes. Thereafter, a lottery was conducted at each study site to randomly allocate households to an intervention group.

Intervention. Intervention group households received a ceramic water filter system designed for use at the household level. The system is shown in Figure 1. It consisted of two locally produced 20 -liter covered plastic buckets, two Katadyn ${ }^{\circledR} 12-\mathrm{cm}$ porous ceramic filter elements (Katadyn Produkte AG, Zurich, Switzerland) and a metal tap fitted into a polyvinyl chloride flange for dispensing the product water. The Katadyn Ceradyn ${ }^{\mathrm{TM}}$ filter elements (candles) have a nominal pore size of $0.2 \mu$ and are impregnated with silver for bacteriostasis. According to the manufacturer, each candle can treat up to 20,000 liters of water depending on frequency of cleaning, and each candle can produce up to 1.5 liters/hour of filtered water depending on turbidity and head pressure.

Members of the intervention group attended a meeting during which they assembled their filter systems and received instructions on filling, using, and cleaning the system. They were encouraged to place the filter on a flat, stable surface that was accessible even to small children; to fill the unit as frequently as necessary using the same water that they previously used for drinking; to have all household members use the filter for drinking, cooking, and cleaning eating utensils; and to clean the candles with a coarse sponge (also provided) whenever they noticed that the flow rate was reduced. They were also instructed to refrain from opening the lower vessel for any reason, and to access the filtered water solely from a cup or other utensil filled from the tap. Apart from answering questions upon distribution of the system or in subsequent visits for sampling and diarrhea surveillance, no hygiene or other instructions, further training, or other explanations were provided as part of the intervention. Control households continued to use their customary practices for collecting, storing, and drawing drinking water.

Surveillance and sampling. Following the distribution of the filter systems, investigators went to each of the study sites four times at approximately six-week intervals to record diarrhea prevalence during the seven days prior to the site visit and to obtain a sample of drinking water for analysis. It was necessary to collect and use such period prevalence data rather than incidence due to the inability to ensure constant access to the study areas for security reasons. Diarrhea was defined as three or more loose stools within a period of 24 hours. For the intervention group, water was sampled directly from the filter taps without flaming the tap so that the sample would reflect normal collection procedure and include any contamination associated with normal use. Water from the control group was collected from the vessel or reservoir used to fill a drinking cup. All samples were preserved between
10

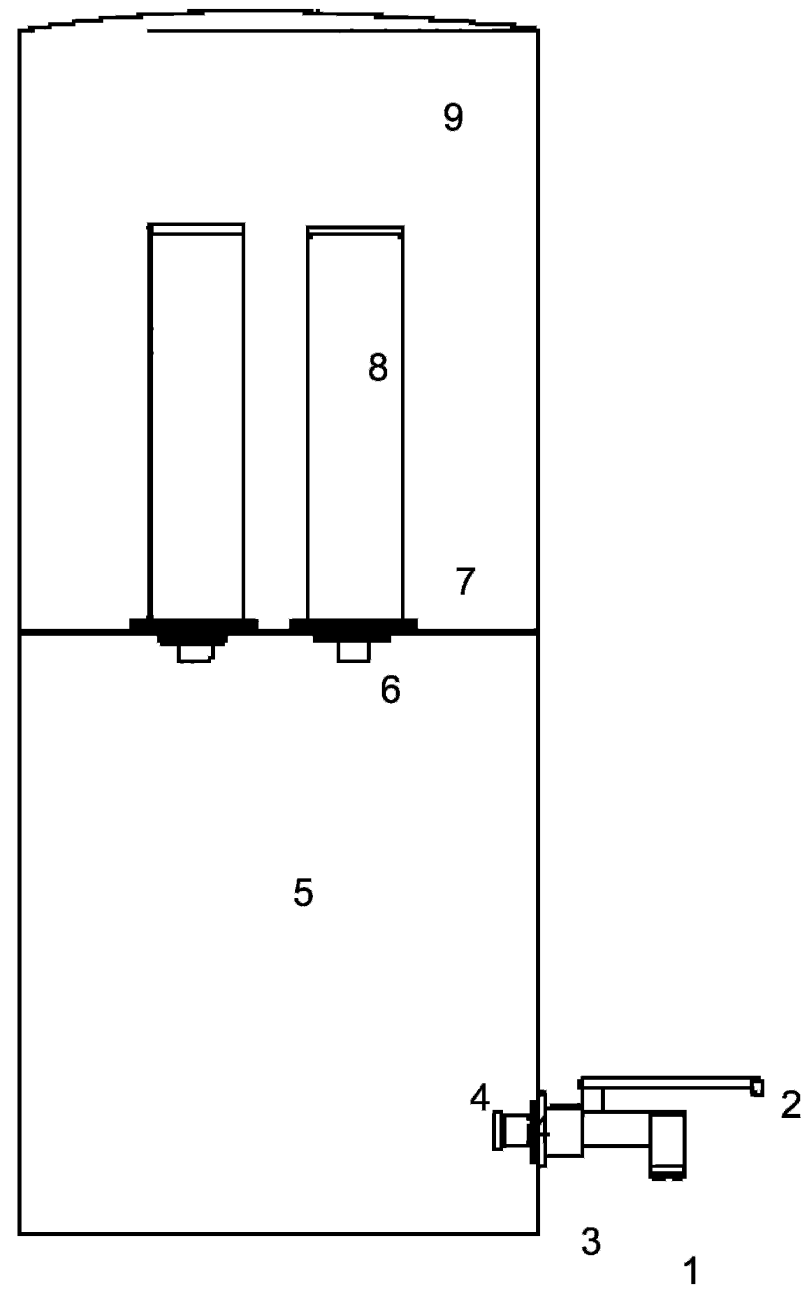

FIGURE 1. Schematic of ceramic filtration unit used by Oxfam GB in pilot field trial, Colombia (not to scale). 1 = heavy-duty metal spigot; 2 = lever to operate ball-type valve; 3 = plastic collar (polyvinyl chloride $[\mathrm{PVC}]) ; 4=\mathrm{PVC}$ nut and rubber gasket securing fitting to receiving/storage container; $5=18$-liter transparent plastic receiving/storage container; $6=$ plastic nut securing candle in place; $7=$ barrier between containers, with a rubber gasket below candle and between containers; $8=12$-cm Katadyn ${ }^{\circledR}$ Cerdayn $^{\text {TM }}$ (Katadyn Produkte AG, Zurich, Switzerland) ceramic filter candle; $9=18$-liter transparent plastic top container; $10=$ hinged top container lid.

$4^{\circ} \mathrm{C}$ and $10^{\circ} \mathrm{C}$ and analyzed within four hours using the membrane filter technique. ${ }^{9}$ Sample water was passed through a $0.45-\mu$ membrane filter (Millipore Corporation, Bedford, MA) and incubated on membrane lauryl sulfate media (Oxoid Ltd., Basingstoke, United Kingdom) at $44 \pm 0.5^{\circ} \mathrm{C}$ for 18 hours in an Oxfam Delagua portable incubator (Robens Institute, University of Surrey, Gilford, United Kingdom). Yellow colonies appearing on the membrane grid were counted and recorded as individual colony-forming units (CFU) of thermotolerant coliforms (TTCs). When a volume of $100 \mathrm{~mL}$ produced a number of CFUs that were too numerous to count (TNTC), the count was recorded as TNTC and assigned a value for purposes of statistical analysis of 300 colonies of TTC per $100 \mathrm{~mL}$. 
Data collection and analysis. Data was recorded on spreadsheets and analyzed using Stata version 8.1 (Stata Corporation, College Station, TX). Data from control and intervention groups were compared by a two-sample $t$-test and Fisher's exact test. Generalized estimating equations were used for the analysis of repeated observations of diarrhea in individuals over time and episodes of diarrhea in families controlling for clustering within households. ${ }^{10}$

Ethics. The assessment of the pilot program was initiated by Oxfam GB and was within the scope of its governmental authority and reporting obligations for operating in Colombia. Written informed consent was obtained from the head of household at the beginning of the program. The expectations and obligations by both the participants and investigators were explained and any questions were answered. It is not believed that the participants were subjected to any additional risks as a result of the project. At the conclusion of the trial, all control group households were offered their filters without charge, and all accepted. Oxfam is continuing to work in each of the communities and thus able to assist with replacement ceramic elements and other components as well as additional filters.

\section{RESULTS}

Baseline. Baseline demographic and other characteristics for each study site and for the aggregate control and intervention groups are shown in Table 1. Baseline data did not show statistically significant differences between intervention and control households in any area measured, including demographics, hygiene practices, sanitation facilities, or water handling practices. However, between study sites, there were potentially important differences. Study participants in Cartagenita were younger (mean age $=16.6$ years, 95\% confidence interval $[\mathrm{CI}]=14.5,18.6)$ than in Curbaradó (21.6, $95 \% \mathrm{CI}=19.0,24.2)$. The average household size in Dabeiba (4.1 persons/household) was larger than the other two communities. In Curbaradó, homes were more likely to be constructed of wood than those in Dabeiba and Cartagenita, a difference that reflects their typical construction on stilts over the river. The mean number of rooms for homes in Dabeiba $(1.8,95 \% \mathrm{CI}=1.5,2.2)$ was less than that in Curbaradó $(2.5$, $95 \% \mathrm{CI}=2.2,2.9)$ or in Cartagenita $(3.1,95 \% \mathrm{CI}=2.5,3.6)$. In terms of hygiene practices, fewer study participants used soap in Dabeiba compared with Curbaradó $(P=0.002)$ and

TABLE 1

Baseline data for each study site and for combined intervention and control groups*

\begin{tabular}{|c|c|c|c|c|c|c|c|}
\hline \multirow[b]{2}{*}{ Characteristic } & \multirow[b]{2}{*}{ Curavaradó } & \multirow[b]{2}{*}{ Dabeiba } & \multirow[b]{2}{*}{ Cartagenita } & \multicolumn{4}{|c|}{ Combined } \\
\hline & & & & Total & Intervention & Control & Difference \\
\hline \multicolumn{8}{|l|}{ Demographics } \\
\hline Total persons & $172(25.3 \%)$ & $309(45.4 \%)$ & 199 (29.3\%) & $680(100 \%)$ & $415(61.0 \%)$ & $265(39.0 \%)$ & - \\
\hline$<5$ years old & $28(16.3 \%)$ & $64(20.7 \%)$ & $50(25.1 \%)$ & $142(20.9 \%)$ & $88(21.2 \%)$ & $54(20.4 \%)$ & NS \\
\hline $5-15$ years old & $50(29.0 \%)$ & $113(36.6 \%)$ & $68(34.2 \%)$ & $231(34.0 \%)$ & $146(35.2 \%)$ & $85(32.1 \%)$ & NS \\
\hline$>15$ years old & $94(54.7 \%)$ & $132(42.7 \%)$ & $81(40.7 \%)$ & $307(45.1 \%)$ & $181(43.6 \%)$ & $126(47.5 \%)$ & NS \\
\hline Total households & $49(35.0 \%)$ & $51(36.4 \%)$ & $40(28.6 \%)$ & $140(100 \%)$ & $76(54.3 \%)$ & $64(45.7 \%)$ & - \\
\hline Wood construction & $42(91.3 \%)$ & $24(49.0 \%)$ & $3(8.3 \%)$ & $69(52.7 \%)$ & $41(56.2 \%)$ & $28(43.3 \%)$ & NS \\
\hline Brick construction & $4(8.7 \%)$ & $25(51.0 \%)$ & $33(91.7 \%)$ & $62(47.3 \%)$ & $32(43.8 \%)$ & $30(51.7 \%)$ & NS \\
\hline Mean number of rooms/household & 2.5 & 1.8 & 3.1 & 2.4 & 2.6 & 2.2 & NS \\
\hline Mean occupants/household & 4.1 & 6.2 & 4.9 & 5.1 & 5.5 & 4.6 & NS \\
\hline Mean occupants/room & 1.9 & 4.1 & 2.0 & 2.7 & 2.9 & 2.5 & NS \\
\hline \multicolumn{8}{|l|}{ Hygiene and sanitation } \\
\hline \multicolumn{8}{|l|}{ Attribute diarrhea mostly to } \\
\hline Water & $39(88.6 \%)$ & $42(85.7 \%)$ & $27(69.2 \%)$ & $108(81.8 \%)$ & $64(86.5 \%)$ & $44(75.9 \%)$ & NS \\
\hline Food & $28(63.6 \%)$ & $21(42.9 \%)$ & $29(74.4 \%)$ & $78(59.1 \%)$ & $46(62.2 \%)$ & $32(55.2 \%)$ & NS \\
\hline Hygiene & $32(59.1 \%)$ & $13(36.7 \%)$ & $23(41.0 \%)$ & $68(45.4 \%)$ & $38(50.0 \%)$ & $30(39.7 \%)$ & NS \\
\hline \multicolumn{8}{|l|}{ Hand-washing events } \\
\hline After defecating & $28(63.6 \%)$ & $30(61.2 \%)$ & $33(86.8 \%)$ & $91(69.5 \%)$ & $52(70.3 \%)$ & $39(68.4 \%)$ & NS \\
\hline Before eating & $40(90.9 \%)$ & $43(87.8 \%)$ & $35(94.6 \%)$ & $118(90.8 \%)$ & $67(91.8 \%)$ & $51(89.5 \%)$ & NS \\
\hline After cleaning child & $19(43.2 \%)$ & $6(12.2 \%)$ & $23(60.5 \%)$ & $48(36.6 \%)$ & $26(35.1 \%)$ & $22(38.6 \%)$ & NS \\
\hline Use soap for hand washing & $39(90.7 \%)$ & $31(63.3 \%)$ & $33(97.1 \%)$ & $103(81.7 \%)$ & $55(78.6 \%)$ & $48(85.7 \%)$ & NS \\
\hline Have soap in home today & $39(92.9 \%)$ & $34(70.8 \%)$ & $34(94.4 \%)$ & $107(81.7 \%)$ & $59(81.9 \%)$ & $48(88.9 \%)$ & NS \\
\hline Had hygiene instruction last 6 months & $32(76.2 \%)$ & $13(29.5 \%)$ & $23(65.7 \%)$ & $68(56.2 \%)$ & $38(55.9 \%)$ & $30(56.6 \%)$ & NS \\
\hline Use sanitation facilities & $39(88.6 \%)$ & $44(89.8 \%)$ & $33(89.2 \%)$ & $116(89.2 \%)$ & $65(89.0 \%)$ & $51(89.5 \%)$ & NS \\
\hline \multicolumn{8}{|l|}{ Type of sanitation facilities } \\
\hline Directly into river & $39(100 \%)$ & 0 & 0 & $39(32.8 \%)$ & $25(36.8 \%)$ & $(32.8 \%)$ & NS \\
\hline Connected toilets or septic tank & 0 & $45(100 \%)$ & $35(100 \%)$ & $80(67.2 \%)$ & $43(63.2 \%)$ & $37(72.5 \%)$ & NS \\
\hline \multicolumn{8}{|l|}{ Water handling practices } \\
\hline \multicolumn{8}{|l|}{ Type of water source } \\
\hline River & $39(86.7 \%)$ & 0 & 0 & $39(29.8 \%)$ & $23(31.5 \%)$ & $16(27.6 \%)$ & NS \\
\hline Rainwater harvesting & $13(28.9 \%)$ & 0 & $1(2.7 \%)$ & $14(10.7 \%)$ & $7(9.6 \%)$ & $7(12.1 \%)$ & NS \\
\hline Yard tap & $0 \%$ & $49(100 \%)$ & $36(97.3 \%)$ & $84(64.1 \%)$ & $45(61.6 \%)$ & $39(67.2 \%)$ & NS \\
\hline Claim to treat water & $34(77.3 \%)$ & $41(83.7 \%)$ & $16(45.7 \%)$ & $91(71.1 \%)$ & $50(71.4 \%)$ & $41(70.7 \%)$ & NS \\
\hline By boiling & $9(27.3 \%)$ & $41(100 \%)$ & $12(92.3 \%)$ & $62(71.3 \%)$ & $32(65.3 \%)$ & $30(78.9 \%)$ & NS \\
\hline With bleach & $10(30.3 \%)$ & 0 & 0 & $10(11.6 \%)$ & $7(14.6 \%)$ & $3(7.9 \%)$ & NS \\
\hline By settling & $14(42.4 \%)$ & 0 & 0 & $14(6.3 \%)$ & $9(18.7 \%)$ & $5(13.2 \%)$ & NS \\
\hline \multicolumn{8}{|l|}{ Access water by } \\
\hline Pouring & 0 & $2(4.5 \%)$ & $4(25.0 \%)$ & $6(5.9 \%)$ & $3(5.7 \%)$ & $3(6.1 \%)$ & NS \\
\hline Dipping in utensil & $30(71.4 \%)$ & $34(77.3 \%)$ & $4(25.0 \%)$ & $68(66.7 \%)$ & $38(71.7 \%)$ & $30(61.2 \%)$ & NS \\
\hline Tap on storage vessel & $12(28.6 \%)$ & $8(18.2 \%)$ & $8(50.0 \%)$ & $28(27.4 \%)$ & $12(22.6 \%)$ & $16(32.6 \%)$ & NS \\
\hline
\end{tabular}

* Demographic data are by individual, remaining data are by household. NS = not significant. 
Cartagenita $(P<0.001)$. Only $29.5 \%$ of the participants from Dabeiba reported having received hygiene education in the six months prior to the study compared with $76.2 \%$ in Curbaradó and $65.7 \%$ in Cartagenita. Unlike Dabeiba and Cartagenita, the population in Curvaradó did not have connected toilets. Finally, only $45.7 \%$ of study participants in Cartagenita reported treating water compared with $77.3 \%$ in Curbaradó $(P=0.004)$ and $83.7 \%$ in Dabeiba $(P<0.001)$.

Water quality. Table 2 shows the arithmetic mean TTC levels for control and intervention households by study community and overall. Differences in baseline TTC levels were not statistically significant between intervention and control groups overall or for any of the study sites. In four rounds of sampling following the introduction of the filters, product water from intervention households was associated with a significant reduction in TTCs. In Caragenita, samples from the filters were completely free of TTCs compared with an arithmetic mean TTC count of $72.2(95 \% \mathrm{CI}=61.0,83.5)$ in the control group. The reduction in the arithmetic mean TTC count was $64.4 \%$ in Curvaradó and $79.1 \%$ in Dabeiba. Overall, the arithmetic mean TTC count among intervention group households was $37.3(95 \% \mathrm{CI}=26.3,48.3)$ compared with 150.6 (95\% CI $=134.8,166.4)$ for the control households, a reduction of $75.2 \%(P<0.0001)$.

The microbiologic performance of the filters was also demonstrated by their capacity to reduce the portion of water samples presenting higher levels of fecal contamination. Table 3 shows the percentage of samples taken that fall into the various World Health Organization (WHO) risk categories for fecal contamination: $0 \mathrm{TTCs} / 100 \mathrm{~mL}$ (in compliance), 1-10 TTCs/100 mL (low risk), 11-100 TTCs/100 mL (intermediate risk), and 101-1,000 TTCs/100 mL (high risk). ${ }^{11}$ At each study community, the filters were associated with a statistically significant improvement in the percentage of samples meeting lower risk categories. Overall, $47.7 \%$ of samples from the intervention households met WHO guidelines for 0 TTCs $/ 100 \mathrm{~mL}$ compared with just $0.9 \%$ for control households $(P<0.001)$. Conversely, $54.5 \%$ of samples from control households had 101-1,000 TTCs/100 mL compared with $10.6 \%$ of samples from intervention households $(P<$ 0.001 ). Although $71.9 \%$ of intervention group samples were in compliance or presented low risk, $91.9 \%$ of samples from control group households presented intermediate or high risk.

Diarrhea prevalence. Data on diarrhea were collected from all but seven households (5\%) who were lost to follow-up. Table 4 shows the odds ratios of diarrhea prevalence by study site and overall, adjusted for age and visit. Overall, persons living within households with filters had a $60 \%$ lower prevalence of diarrhea than their counterparts in control households. Adjusting for age and visit and controlling for clustering at the household, the odds ratio (OR) was $0.40(95 \%$ $\mathrm{CI}=0.25,0.63, P<0.001)$ for all persons participating in the

TABLE 2

Arithmetic mean thermotolerant coliform levels (and 95\% confidence intervals) for each study community

\begin{tabular}{lccc}
\hline \multicolumn{1}{c}{ Site } & Control & Intervention & $P$ (t-test) \\
\hline Curvarado & $154.4(124.0,185.0)$ & $50.3(30.0,70.9)$ & $<0.0001$ \\
Dabeida & $220.1(193.5,246.7)$ & $45.9(26.7,65.1)$ & $<0.0001$ \\
Cartagenita & $72.2(61.0,83.5)$ & 0 & $<0.0001$ \\
Overall & $150.6(134.8,166.4)$ & $37.3(26.3,48.3)$ & $<0.0001$ \\
\hline
\end{tabular}

TABLE 3

Percentage of samples from control and intervention households by World Health Organization (WHO) risk category for each study community and overall*

\begin{tabular}{|c|c|c|c|c|c|}
\hline \multirow[b]{2}{*}{ Site } & \multicolumn{5}{|c|}{ Percentage of samples by WHO risk category (WHO, 1997) } \\
\hline & $\begin{array}{c}0 \\
\text { TTC/100 } \\
\mathrm{mL}\end{array}$ & $\begin{array}{c}1-10 \\
\text { TTC/100 } \\
\mathrm{mL}\end{array}$ & $\begin{array}{c}11-100 \\
\text { TTC/100 } \\
\mathrm{mL}\end{array}$ & $\begin{array}{c}\text { 101-1,000 } \\
\text { TTC/100 } \\
\text { mL }\end{array}$ & $\left(\begin{array}{c}P H^{2} \\
\left(\mathrm{chi}^{2}\right)\end{array}\right.$ \\
\hline Curvarado & & & & & $<0.001$ \\
\hline Control & $0 \%$ & $9.86 \%$ & $39.44 \%$ & $50.70 \%$ & \\
\hline Intervention & $23.47 \%$ & $33.67 \%$ & $29.56 \%$ & $13.27 \%$ & \\
\hline Dabeida & & & & & $<0.001$ \\
\hline Control & $0 \%$ & $10.7 \%$ & $16.7 \%$ & $72.6 \%$ & \\
\hline Intervention & $41.58 \%$ & $28.71 \%$ & $15.84 \%$ & $13.86 \%$ & \\
\hline Cartagenita & & & & & $<0.001$ \\
\hline Control & $2.56 \%$ & $1.28 \%$ & $57.69 \%$ & $38.46 \%$ & \\
\hline Intervention & $100 \%$ & $0 \%$ & $0 \%$ & $0 \%$ & \\
\hline Overall & & & & & $<0.001$ \\
\hline Control & $0.86 \%$ & $7.30 \%$ & $37.34 \%$ & $54.51 \%$ & \\
\hline Intervention & $47.66 \%$ & $24.22 \%$ & $17.58 \%$ & $10.55 \%$ & \\
\hline
\end{tabular}

study and $0.40(95 \% \mathrm{CI}=0.21,0.76, P=0.005)$ for children less than five years of age. However, among individual study sites, results were statistically significant only in Cartagenita, where the filter was protective for all ages $(\mathrm{OR}=0.21,95 \%$ $\mathrm{CI}=0.08,0.41, P<0.001)$ and for children less than five years of age $(\mathrm{OR}=0.19,95 \% \mathrm{CI}=0.06,0.58, P=0.004)$. In Dabeiba, the filters showed some evidence of protection against diarrhea, but the difference did not achieve conventional levels of statistical significance. In Curvaradó, the prevalence of diarrhea reported by members of the intervention group was not statistically different from that of the control group.

Association between water quality and diarrhea prevalence. To explore the apparent association between fecal contamination of drinking water and diarrhea prevalence, ORs were computed against log 10 TTC counts, controlling for household clustering, age, and visit. The odds of diarrhea increased with $\log 10$ TTC counts both for all ages $(\mathrm{OR}=$ $1.48,95 \% \mathrm{CI}=1.12,1.95, P=0.006)$ and for children less than five years of age $(\mathrm{OR}=1.47,95 \% \mathrm{CI}=1.01,2.15, P=$ 0.046). The increased odds of diarrhea with increased TTC levels suggest a dose-response relationship between fecal contamination of water and diarrheal disease.

\section{DISCUSSION}

This study was conducted to assess a pilot intervention by Oxfam GB using household-based ceramic filters to prevent

TABLE 4

Odds ratios of diarrhea among all participants and for children less than five years of age by study site adjusted for age and visit and controlling for clustering by household*

\begin{tabular}{|c|c|c|c|c|c|c|}
\hline \multirow[b]{2}{*}{ Site } & \multicolumn{3}{|c|}{ All age } & \multicolumn{3}{|c|}{ Children $<5$ years of age } \\
\hline & OR & $95 \% \mathrm{CI}$ & $P$ & OR & $95 \% \mathrm{CI}$ & $P$ \\
\hline Curvarado & 0.87 & $0.31,2.39$ & 0.781 & 1.37 & $0.21,8.87$ & 0.743 \\
\hline Dabeida & 0.49 & $0.21,1.13$ & 0.095 & 0.60 & $0.24,1.56$ & 0.297 \\
\hline Cartagenita & 0.21 & $0.10,0.41$ & $<0.001$ & 0.19 & $0.06,0.58$ & 0.004 \\
\hline Overall & 0.40 & $0.25,0.63$ & $<0.001$ & 0.40 & $0.21,0.76$ & 0.005 \\
\hline
\end{tabular}

$\mathrm{OR}=$ odds ratio; $\mathrm{CI}=$ confidence interval 
diarrheal disease in Colombia. Overall, the filters demonstrated a capacity to reduce fecal bacteria in source water, and thus improve drinking water quality. The filters were also associated with a significant reduction in the prevalence of diarrhea. These findings are consistent with the microbiologic performance and health impact of the only other intervention trials involving ceramic water filters used at the household level. $8,12,13$

It is noteworthy, however, that although the filters were protective overall, there was a substantial range in the results among the three settings comprising the overall study. Although the filters completely eliminated TTCs from water samples in Cartagenita, the mean reduction was only $79 \%$ in Dabeiba and $75 \%$ in Curvaradó. The reduction in all age diarrhea prevalence in Cartagenita was correspondingly greater than in Dabeiba and Curvaradó.

Although the overall performance of the filters is promising, it is important to explore whether the differences in results in the three study settings can be explained and thus provide future guidance in the use of this intervention. The description of the study settings and certain baseline data did show some potentially important differences in the communities. Curvaradó, where the intervention was least effective, was the most remote of the study settings. Homes in Curvaradó are constructed directly over the river into which most people defecate; thus, inhabitants are arguably the most regularly exposed to fecal pathogens via pathways other than drinking water. Cartagenita, which benefited most from the intervention, had a younger but less dense population, were generally living in larger and brick-constructed homes in an agricultural area, and were less likely to be treating the water in their homes. The presence of local health promoters in Cartagenita could have also played an important role in the success of the intervention even though they were not directly involved in its deployment, maintenance, or support. Dabeiba, where there was some evidence that the intervention was effective, but less so than in Cartagenita, was a more peri-urban setting with the smallest, most crowded homes, and had statistically lower levels of hygiene instruction and soap for hand washing.

These differences may suggest possible reasons for the range of microbiologic performance and health impact of the filters among the three study communities. However, given the heterogeneity of results in household-based interventions generally, further research is necessary to guide decisions about the appropriateness of the intervention in particular settings, or perhaps the need to supplement the hardware in certain cases with additional programmatic support. ${ }^{14}$ This research should include the exploration of behavioral and sociocultural factors that we did not measure or investigate.

Our results showed an association between the microbiologic performance of the filters and their health impact. This was demonstrated by the increased odds of diarrhea with log 10 increases in TTC counts in sampled drinking water from the home. Although such a relationship is the basis for the recently revised drinking water quality guidelines, ${ }^{15}$ a recent systematic review found that in the case of general diarrhea (as opposed to cholera), studies do not demonstrate a clear relationship between disease and microbial water quality at the point of use. ${ }^{16}$ At the same time, both that review and others ${ }^{5,6}$ have shown that household interventions to improve water quality are protective against diarrhea. The dose- response relationship that we observed between TTC counts and disease suggests the underlying biologic basis for this consistent epidemiologic evidence and is consistent with the hazard-based approach under the water quality guidelines.

Finally, it should be noted that due to in part to its having been undertaken in the context of a pilot intervention in remote settings, the design of this study had certain shortcomings. First, this study was not blinded, either at the level of the intervention or the assessor. Certain studies of householdbased water treatment interventions that have used a placebo-controlled, double-blind design found no statistically significant difference between intervention and control groups, although other single-blinded studies have found the intervention to be effective, much like the great majority of studies of household-based water treatment. ${ }^{17-21}$ Second, this study assessed diarrhea using seven-day recall. Research has suggested that recall periods in excess of 48 hours tend to understate the actual frequency of the disease. ${ }^{22}$ Third, as a result of the remoteness of the study sites and the lack of on-site investigators, there was no rigorous means of assessing compliance with the intervention. Finally, although the intervention was randomly allocated within each study setting following a method that ensured an appropriate generation of the allocation sequence and concealment of such sequence, the selection of the study communities was not random but done by Oxfam in an attempt to obtain a representation of the types of settings in which it operates in Colombia.

Notwithstanding these shortcomings, this assessment does provide additional evidence of the potential value of household water treatment in the prevention of diarrheal disease among a vulnerable population. At the same time, it demonstrates the range of effectiveness of such interventions and thus the need to consider carefully the circumstances prevailing in a target community when choosing among possible options.

Received April 1, 2005. Accepted for publication May 23, 2005.

Acknowledgments: We thank Fredy Vidal and Luz Marina Londono (Oxfam GB-Colombia) for conducting the field work in connection with this study, Timothy Forster (Oxfam GB) for providing technical support, and Joseph Brown (University of North Carolina, Chapel Hill, NCV) for supplying the filter schematic. We also thank the study participants in the communities of Curvaradó, Dabeiba, and Cartagenita.

Financial support: Thomas Clasen and Simon Collin are on the staff of the London School of Hygiene and Tropical Medicine, which receives funding for water research from Unilever, Ltd. Gloria Garcia Parra is on the staff of Oxfam (United Kingdom). Thomas Clasen and Sophie Boisson serve as consultants to International Health Research Associates, Ltd., a consulting group whose work includes laboratory and field assessments of water treatment technologies. Apart from their normal compensation, no special funding was provided to the authors to support this research.

Disclaimers: As noted above, the research of Thomas Clasen, Sophie Boisson, and Simon Collin is supported in part by Unilever Ltd. and International Health Research Associates, Ltd. whose activities may include the assessment and promotion of household-based water treatment technologies. However, to the best of the authors' knowledge, none of these companies manufacture or sell ceramic water filters.

Authors' addresses: Thomas Clasen and Simon Collin, Department of Infectious and Tropical Diseases, London School of Hygiene and Tropical Medicine, Keppel Street, London WC1E 7HT, United Kingdom, E-mails: thomas.clasen@lshtm.ac.uk and simon.collin@ 1shtm.ac.uk. Gloria Garcia Parra, Oxfam GB, 274 Banbury Road, 
Oxford OX2 7DZ, United Kingdom, E-mail: GGarcia@ oxfam.org.uk. Sophie Boisson, International Health Research Associates, Ltd., 22 Clyro Court, Tollington Park, London N4 3AQ, United Kingdom, E-mail: s_boisson@hotmail.com.

\section{REFERENCES}

1. Kosek M, Bern C, Guerrant RL, 2003. The global burden of diarrhoeal disease, as estimated from studies published between 1992 and 2000. Bull World Health Organ 81: 197-204.

2. Parashar UD, Bresee JS, Glass RI, 2003. The global burden of diarrhoeal disease in children. Bull World Health Organ 81: 236.

3. Pan American Health Organization, 2004. Country Profiles, Basic Health Indicators (Colombia). Washington, DC: Pan American Health Organization. Available from http://www.paho.org/ English/DD/AIS/cp_170.htm)

4. WHO/UNICEF, 2004. Meeting the MDG Drinking Water and Sanitation Target: A Mid-Term Assessment of Progress. Geneva and New York: World Health Organization and UNICEF.

5. Clasen T, Roberts I, Rabie T, Schmidt W, Cairncross S, 2005. Interventions to improve water quality for preventing infectious diarrhea. The Cochrane Library, Issue 4, 2005. Oxford: Update Software.

6. Fewtrell L, Kaufmann R, Kay D, Enanoria W, Haller L, Colford $\mathrm{J}, 2005$. Water, sanitation, and hygiene interventions to reduce diarrhoea in less developed countries: a systematic review and meta-analysis. Lancet Infect Dis 5: 42-52.

7. WHO, 2002. World Health Report. Geneva: World Health Organization.

8. Clasen T, Brown J, Suntura O, Collin S, 2004. Reducing diarrhoea through household-based ceramic filtration of drinking water: a randomized, controlled trial in Bolivia. Am J Trop Med Hyg 70: 651-657.

9. Standard Methods for the Examination of Water and Wastewater, 2000. Washington, DC: American Public Health Association/ American Water Works Association/Water Environment Federation.
10. Zeger SL, Liang KY, 1986. Longitudinal analysis using generalized linear models. Biometrika 73: 13-22.

11. WHO, 1997. Guidelines for Drinking Water Quality. Second edition. Volume 3. Geneva: World Health Organization.

12. Universidad Rafael Landivar, Instituto de Investigaciones Económicas y Sociales, 1995. Contra la Morbilidad Infantil: Filtros Artesanales y Educación. Guatemala: Revista de Estudios Sociales no. 53, IV Epoca.

13. du Preez M, 2004. Field results from a ceramic filter intervention study in rural South Africa and Zimbabwe. Presentation at the IWA 4th World Water Congress, Marrakech, Morocco, September 19-24, 2004

14. Clasen T, Cairncross S, 2004. Household water treatment: refining the dominant paradigm. Trop Med Int Hyg 9: 187-191.

15. WHO, 2004. Guidelines for Drinking Water Quality. Third edition. Volume 1. Geneva: World Health Organization.

16. Gundry S, Wright J, Conroy R, 2004. A systematic review of the health outcomes related to household water quality in developing countries. $J$ Water Health 2: 1-13.

17. Colford JM, Rees JR, Wade TJ, Khalakdina A, Hilton JF, Ergas IJ, Burns S, Benker A, Ma C, Bowen C, Mills DC, Vugia DJ, Juranek DD, Levy DA, 2002. Participant blinding and gastrointestinal illness in a randomized, controlled trial of an inhome drinking water intervention. Emerg Infect Dis 8: 29-36.

18. Kirchhoff LV, McClelland KE, Do Carmo Pinho M, Araujo JG, de Sousa MA, Guerrant RL, 1985. Feasibility and efficacy of in-home water chlorination in rural North-eastern Brazil. $J$ Hyg (Lond) 94: 173-180.

19. Austin CJ, 1993. Chlorinating household water in the Gambia. Proceedings of the 19th WEDC Conference. Accra, Ghana, 90-92.

20. Conroy RM, Elmore-Meegan M, Joyce T, McGuigan KG, Barnes J, 1996. Solar disinfection of drinking water and diarrhoea in Maasai children: a controlled field trial. Lancet 348: 1695-1697.

21. Conroy RM, Meegan ME, Joyce T, McGuigan K, Barnes J, 1999. Solar disinfection of water reduce diarrhoeal disease: an update. Arch Dis Child 81: 337-338.

22. Boerma JT, Black RE, Sommerfelt AE, Rutstein SO, Bicego GT, 1991. Accuracy and completeness of mothers' recall of diarrhoea occurrence in pre-school children in demographic and health surveys. Int J Epidemiol 20: 1073-1080. 